\title{
A satisfação do beneficiário da saúde suplementar sob a perspectiva da qualidade e integralidade
}

\author{
I 1 Raphaella Fagundes Daros, ${ }^{2}$ Rafael da Silveira Gomes, \\ ${ }^{3}$ Fabio Hebert da Silva, ${ }^{4}$ Tatiana Coelho Lopes I
}

Resumo: Este estudo teve como objetivo analisar o conceito de qualidade a partir da demanda dos beneficiários da Saúde Suplementar, na perspectiva $\mathrm{da}$ integralidade, considerando as relaçôes entre satisfação, assimetria de informação e cuidado em saúde. Foi realizada a análise de uma amostragem de 1.013 e-mails enviados para a Central de Relacionamento da Agência Nacional de Saúde Suplementar de beneficiários da região sudeste, o que resultou na categorização Acesso aos Serviços e Continuidade do Cuidado, com as seguintes subcategorias: Negação; Dificuldade elou Imposição de Condicionantes; e Rede de Prestadores Restrita. Os beneficiários enfatizaram aspectos relacionados ao acesso aos serviços e à continuidade do cuidado que explicitam que as estratégias de redução de custos das operadoras têm afetado a qualidade e a integralidade do cuidado. Os relatos apontam que, para além da negação do acesso aos serviços e procedimentos, os beneficiários se vêem diante da restrição da continuidade do cuidado. Os resultados nos colocam o desafio de questionar a estruturação desse setor, cujos contratos se baseiam na definição de um rol de procedimentos e as estratégias de redução de custos se configuram como instrumento de restrição ao próprio direito à saúde, para além do respeito necessário ao direito do consumidor.

> Palavras-chave: saúde suplementar; satisfação dos beneficiários; qualidade; integralidade.

\author{
1 Universidade Federa \\ Fluminense. Niterói-RJ, Brasil \\ (raphadaros@gmail.com). \\ 2 Universidade Federal do \\ Espírito Santo, Departamento \\ de Psicologia. Vitória-ES, Brasil \\ (rafaelsgomes@gmail.com). \\ ${ }^{3}$ Universidade Federal do \\ Espírito Santo, Departamento \\ de Psicologia. Vitória-ES, Brasil \\ (fabiohebert@gmail.com). \\ ${ }^{4}$ Hospital Sofia Feldman. \\ Belo Horizonte-MG, Brasil \\ (tatianacoelholopes@gmail.com).
}

Recebido em: 13/08/2015 Aprovado em: 15/12/2015 


\section{Introdução ${ }^{1}$}

A Constituição Federal de 1988 legitimou a saúde como um direito de todos e dever do Estado, com status de bem público, porém livre à iniciativa privada, cujas instituições podem participar de forma complementar ao Sistema Único de Saúde (BRASIL, 1988). Desse modo, o sistema de saúde brasileiro é composto por dois subsistemas: o público e o privado (PIETROBON; PRADO; CAETANO, 2008). Nesse cenário, os serviços privados, que nas décadas de 1970 e 1980 vinham se ampliando significativamente, passam a configurar o setor de saúde suplementar, sendo reconhecidos como parte da política nacional de saúde, sem, no entanto, ter suas atividades regulamentadas, normatizadas, orientadas e fiscalizadas. Isso só ocorre em 2000, com a criação da Agência Nacional de Saúde Suplementar (ANS) pela Lei no 9.961, de 28 de janeiro de 2000.

Diante da ausência de uma legislação específica para o setor da saúde suplementar, a norma mais frequente para a tentativa de resolução dos conflitos nas relações entre beneficiários e as operadoras dos planos de saúde era o Código de Defesa do Consumidor, sendo o PROCON a instituição de referência. Segundo Andrade, Maia e Rodrigues (2013) e Alves, Bahia e Barroso (2009), as grandes questôes que levavam os beneficiários a acionar o sistema judiciário, geralmente decorrentes de contratos "injustos e excludentes”, eram a restrição de cobertura, o acesso aos serviços, os aumentos dos preços praticados e a interrupção do tratamento de maneira unilateral, juntamente com questôes relacionadas à portabilidade, descredenciamento de rede, entre outras questôes referentes mais estritamente ao direito do consumidor.

Nesse contexto, a ANS passa a atuar basicamente na promoção da defesa do interesse público na assistência suplementar à saúde, regulando prioritariamente as relações contratuais dos beneficiários com as operadoras dos planos de saúde e, indiretamente, com os prestadores a estas vinculados, visando à garantia do acesso à assistência suplementar à saúde. Sua atuação, inicialmente, foi centrada em três pontos principais: sustentabilidade do mercado; direito dos consumidores; produtos, valores e coberturas. Além disso, a agência teria como atribuição o controle da assimetria da informação e a ampliação da participação do beneficiário no setor. A incidência da prática regulatória na sustentabilidade do mercado tem destacado as ações direcionadas para a intermediação dessas relaçôes contratuais, as quais têm se configurado então como competência mais 
visibilizada da agência. $\mathrm{O}$ investimento em tais relaçōes, nos últimos anos, parece ter garantido a ampliação e estabilidade do setor, com a democratização do acesso aos serviços, impulsionada ao mesmo tempo pelo aumento do poder aquisitivo de parcela considerável da população, ocasionada pelo desenvolvimento socioeconômico (SANTOS; MALTA; MERHY, 2008).

Atualmente, passados quinze anos desde a fundação da agência, apesar dos desafios ainda encontrados na busca da garantia do acesso aos serviços de saúde suplementar, a consolidação das conquistas nesse âmbito abre espaço para a emergente discussão acerca da questão da qualidade. A qualidade, aqui, pode ser traduzida em um conjunto de políticas, diretrizes e açôes que busca tanto a qualificação das relações contratuais e regulatórias quanto o parâmetro fundamental da satisfação dos beneficiários (SILVA JÚNIOR et al., 2008).

Sisson et al. (2011) apontam a satisfação dos usuários como um parâmetro importante para ações de planejamento, gestão, monitoramento e avaliação das prestadoras de serviços de saúde, contribuindo na ampliação do nível de qualidade dos serviços prestados. A percepção dos usuários contribui para produção de informações tanto para a implementação de ações na área, quanto para a regulação das relações com entes públicos e privados no setor saúde. No entanto, a inclusão da satisfação do beneficiário e da qualidade como parâmetros nos coloca um desafio, já que se trata de indicadores extremamente complexos: as experiências de cuidado que operam dentro de uma lógica contratual; certas dimensôes do acesso aos serviços e da continuidade do cuidado que extrapolam tal lógica contratual; criação de demanda e expectativa de consumo para procedimentos e tecnologias de ponta que não poderão ser contempladas; uma perspectiva de rede como conjunto de prestadores de serviço e que termina por fragmentar o cuidado em especialidades; disponibilidade de recursos e conflitos contratuais entre operadoras e prestadores.

Vários programas da ANS, tais como o Índice de Desempenho da Saúde Suplementar, que avalia o desempenho das operadoras, o QUALISS, que avalia a qualificação de prestadores, e o Programa de Acreditação, que tem como objetivo certificar a qualidade assistencial das operadoras de planos de saúde, discutem e abordam a questão da melhoria do atendimento ao beneficiário segundo óticas distintas. Investigar o conceito de qualidade na saúde suplementar desde a perspectiva dos diferentes grupos passa a ser então de fundamental importância 
no desenvolvimento e aprimoramento das análises e divulgação de informaçōes do setor. Com esse objetivo, entre outras açōes, a ANS tem incentivado e promovido pesquisas de satisfação do beneficiário, sem, contudo, chegar a relacionar ou inferir qual a percepção destes acerca do conceito de qualidade em saúde suplementar e sua relação com a integralidade.

Verifica-se uma tendência, no setor da saúde suplementar, de lançar mão das estratégias produzidas pelo campo da Saúde Coletiva como recursos gerenciais e até mesmo de propaganda dos cuidados ofertados pelas operadoras (MALTA et al., 2004). No entanto, quando essas práticas são desenvolvidas sem considerar ações para humanização do cuidado e o investimento na transformação dos modos de relação estabelecidos entre trabalhadores de saúde e beneficiários, a capacidade de promover mudanças significativas na qualidade do atendimento às necessidades dos últimos é limitada, mantendo-se ainda centrada na doença e na oferta de um cuidado fragmentado (PINHEIRO; SILVA JR., 2007), o que torna a discussão da integralidade, na perspectiva de qualificar o cuidado prestado, um desafio na saúde suplementar.

A discussão da integralidade no Brasil vem ganhando uma dimensão sociopolítica mais ampla que em outros países. Direciona-se ao esforço de estabelecimento, manutenção e ampliação dos direitos sociais recém-adquiridos em meio a um contexto constituído por grandes desigualdades socioeconômicas e culturais e marcado pela insuficiência das redes assistenciais, organizadas a partir de modelos centralizados e verticalizados de gestão. Como resultado, temse uma grande lacuna entre as necessidades dos usuários e os serviços ofertados. (SILVA JÚNIOR et al., 2008).

No campo da saúde suplementar, especificamente, observamos a fragilidade da produção acadêmica no que se refere ao princípio da integralidade, tanto pela incipiência de pesquisas e estudos ligados à temática, como pelo apontamento de que estratégias indutoras da integralidade são práticas embrionárias que têm encontrado muita resistência das operadoras e prestadores, cuja organização dos serviços segue reafirmando a fragmentação do cuidado e na perpetuação de uma lógica procedimento-centrada (GARBIN et al., 2013).

No que se refere à temática da qualidade, podemos observar uma maior aproximação da produção acadêmica (DILÉLIO et al., 2014; CARVALHO; FORTES; GARRAFA, 2013; PORTELA et al., 2010; UGÁ et al., 2009, SILVA 
JUNIOR et al. 2008, VERAS, 2012; 2011; VERAS et al., 2008). Em termos

gerais, aponta-se a incipiência do debate e das ações relacionadas à temática, mas se afirma a expectativa de uma maior regulação qualitativa diante do contexto do pouco avanço da qualidade da assistência. A avaliação dos serviços de saúde ganha destaque nos últimos anos, tanto como consequência do aumento da pressão social dos beneficiários e dos clientes corporativos do campo da saúde suplementar quanto pelo reconhecimento do movimento governamental acerca da importância estratégica na qualificação da assistência e planejamento do sistema de saúde.

Contudo, os indicadores utilizados permanecem centrados nos critérios da oferta, acesso e utilização de procedimentos e, principalmente, no cumprimento das cláusulas contratuais. Nesse sentido, entendemos, como alguns dos estudiosos da temática (ESCRIVÃO JÚNIOR; KOYAMA, 2007; GERSCHMAN, 2008), que a facilidade de acesso, sob o lastro do incentivo de uma prática procedimentocentrada, não necessariamente resulta numa melhor qualidade do nível de saúde da população atendida. De acordo com Silva Júnior et al. (2008), a qualidade da atenção à saúde requer modelos de atenção que articulem ações, com efetividade comprovada, desenvolvidas em uma relação humanizada entre profissionais e usuários, apreendida de forma positiva por estes em termos de suas expectativas. Desse modo, a construção de "linhas de cuidado" parece uma tática interessante para subsidiar as metodologias e as mudanças consideradas estratégicas na direção da ampliação da qualidade em saúde.

Reconhece-se, porém, uma tentativa da ANS, por meio de práticas regulatórias, de sensibilizar e transformar, por um lado, as operadoras de planos de saúde em gestoras da saúde, e por outro, os prestadores de serviços em produtores de cuidado, induzindo uma mudança de paradigma que tem sido relacionada com a chamada transição tecnológica no setor da saúde suplementar. Contudo, a discussão da qualidade, na maior parte dos casos, fica sob a determinação da relação custoefetividade. Mesmo quando há investimentos em atividades de promoção e prevenção, reunidos atualmente sob os modelos de atenção gerenciada, as ações funcionam mais como produto de marketing do que como diretriz de um modelo assistencial, visando de fato ao cuidado à saúde. (MENESES et al., 2013; UGÁ et al., 2009; MARTINS et al., 2009; FREITAS et al., 2011).

Desse modo, observamos que a construção de novos modos de assistência e a reorganização dos processos de trabalho, ainda que possam apontar para 
uma transformação qualitativa da assistência, mais condizente com o modelo abraçado pelo SUS, ainda são condicionadas pelo mercado e limitadas pelos interesses econômicos das operadoras e prestadores.

Partindo dos referenciais do campo da Saúde Coletiva, entendemos que a saúde é determinada socialmente e que, portanto, está atrelada a fenômenos que incluem fatores biológicos, psicológicos, sociais, culturais, econômicos e ambientais. Assim, as necessidades em saúde emergem de uma inserção singular dos sujeitos na complexidade de determinados contextos, manifestando-se em variados tipos e graus conforme a organização social de um determinado território. Por isso, compreendemos que as demandas aos serviços não podem ser analisadas exclusivamente a partir de uma perspectiva objetiva monitorada por meio de indicadores tradicionais. As necessidades de saúde expressam a cultura, os valores, os projetos e desejos dos sujeitos individuais e coletivos que procuram os serviços (SILVA; BATISTELLA; GOMES, 2007). Nesse contexto, a satisfação do beneficiário emerge como indicador fundamental para a avaliação da qualidade do setor, justificada pela necessidade de se ter o usuário do sistema como foco e prioridade.

Apesar de alguns autores afirmarem a experiência do usuário como parte indissociável do projeto tecnoassistencial e destacarem a importância da análise da satisfação para ações de planejamento, monitoramento e avaliação das prestadoras de serviços de saúde (compreendendo-a como contribuição indispensável na ampliação do nível de qualidade dos serviços prestados), enfatizam-se também a inconsistência teórica do conceito de satisfação e certa polissemia, que contribui para diminuir seu potencial analítico.

Os estudos direcionados à satisfação dos beneficiários chamam atenção para a complexidade e contradição que essa dimensão implica, dificultando o estabelecimento de critérios para sua mensuração. $\mathrm{Na}$ ausência de critérios mais claros, muitas vezes, a satisfação fica circunscrita ao âmbito da manifestação das queixas e reclamações dos beneficiários como consumidores dos planos de saúde contratados. O problema é que nessa direção só há a possibilidade de gerar autuações e penalidades quando essa satisfação confusa não é alcançada. Nesse contexto, ainda são muito inexpressivas as abordagens que caminhem por uma via metodológica mais inclusiva, através da investigação das opiniōes 
dos beneficiários sobre a qualidade dos processos de cuidado na relação com a integralidade das açôes, a singularidade das demandas por saúde e alguma perspectiva de rede de produção de saúde.

Portanto, apesar de reconhecer o acesso como dimensão fundamental e ainda em processo de consolidação, é preciso, ao mesmo tempo, avançar no debate acerca dos sentidos da qualidade da regulação e, principalmente, da qualidade assistencial e sua relação com a integralidade no setor da saúde suplementar, uma vez que parece não haver atualmente, seja na via político-institucional ou no âmbito acadêmico, um consenso acerca desses conceitos.

Em meio a esse cenário, este estudo teve como objetivo geral analisar o conceito de qualidade a partir da demanda dos beneficiários do setor de saúde suplementar, na perspectiva da integralidade, considerando as relaçóes entre satisfação, assimetria de informação e cuidado em saúde. Procuramos, assim, entre outros fatores, contribuir para ampliar a compreensão acerca de quais requisitos compóem, em termos gerais, a satisfação dos beneficiários, em uma tentativa de mapear a lacuna existente entre as suas necessidades singulares e os serviços ofertados pelo sistema de saúde suplementar.

\section{Metodologia}

Realizamos um estudo qualitativo de caráter exploratório, operacionalizado em três etapas. A primeira consistiu na realização de uma revisão integrativa da produção científica relacionada ao setor da saúde suplementar entre os anos de 2000 e 2014, que teve como principal objetivo evidenciar as lacunas e dimensôes abordadas ou privilegiadas quanto aos temas em análise. A segunda etapa, cujos resultados compõem o recorte e conteúdo específicos apresentados neste texto, correspondeu à realização da análise de uma amostragem de e-mails enviados para a Central de Relacionamento no site da ANS, com o objetivo de acessar diretamente as demandas dos beneficiários, traduzidas pelo envio de textos que, apesar de contarem com uma restrição de caracteres, não passaram por nenhuma espécie de filtro ou alteração da instituição. A terceira e última etapa consistiu na realização de grupos focais com os técnicos e especialistas em regulação de três Núcleos de Atendimento da ANS situados na Região Sudeste, cujas principais temáticas de debate e análise concentraram-se nas demandas dos 
beneficiários que buscavam pessoalmente a instituição na busca de informações e/ou resolução de conflitos e impasses estabelecidos com os prestadores e operadoras regulamentados pelo setor, possibilitando nosso acesso à experiência dos servidores no encontro cotidiano com os beneficiários.

O projeto de pesquisa foi aprovado por um Comitê de Ética em Pesquisa com seres humanos (Parecer 1.116.251) e seguiu as recomendaçôes da resolução $n^{\circ}$ 466/12 do Conselho Nacional de Saúde.

Diante da amplitude das informações produzidas no estudo, optamos por dar visibilidade neste artigo à análise realizada mais especificamente na segunda etapa, cuja constituição do corpus de análise se deu a partir de um recorte temporal e espacial da amostragem de e-mails citada. Em relação ao recorte temporal, definimos que a análise seria realizada com e-mails enviados durante o período de um ano, a partir da implantação da Notificação de Intermediação Preliminar, ${ }^{2}$ em 19 de março de 2014.

No período de 19 de março de 2014 a 19 de março de 2015, foram enviados 19.969 e-mails. Quanto ao recorte espacial, optamos por restringir a amostra aos beneficiários residentes nas unidades federativas que compõem a região sudeste do Brasil (ES, MG, RJ e SP), uma vez que essa região concentra, segundo dados da ANS (março de 2015), 61,3\% da população de beneficiários do país e 69,4\% das demandas por e-mail recebidas pela ANS no período abarcado pela pesquisa. Do total, 13.856 e-mails correspondiam a beneficiários residentes nessa região.

Para a elaboração do plano amostral, foram utilizados métodos amostrais probabilísticos, a fim de obter representatividade para o conjunto de e-mails enviados por beneficiários demandantes da Região Sudeste do Brasil. Para o cálculo do tamanho da amostra, considerou-se um intervalo de confiança de 95\% e margem de erro de 3 pontos percentuais, resultando em uma amostra de 1.013 e-mails. A seleção foi aleatória, respeitando a proporcionalidade por unidade federativa e a categoria temática utilizada como classificação padrão no sistema de registro da Central de Relacionamentos da ANS, conforme detalhado na Tabela 01. Assim a amostra foi composta por 21 e-mails do Espírito Santo, 104 de Minas Gerais, 279 do estado do Rio de Janeiro e 609 do estado de São Paulo. 
Tabela 1. Distribuição do número (n) de e-mails aleatórios selecionados de acordo a proporcionalidade federativa e categoria temática utilizada como classificação padrão no sistema de registro da Central de Relacionamentos da ANS, Região Sudeste, 2014-2015

\begin{tabular}{|l|c|c|c|c|c|}
\hline Categorias & ES & MG & RJ & SP & Total \\
\hline Prazos Máximos para Atendimento & 8 & 27 & 64 & 148 & 247 \\
\hline Reembolso & 2 & 6 & 53 & 75 & 136 \\
\hline Rede de Atendimento (rede conveniada) & 2 & 13 & 32 & 74 & 121 \\
\hline $\begin{array}{l}\text { Gerenciamento das Açães de Saúde por Parte } \\
\text { da Operadora (autorizações prévias, franquia, } \\
\text { co-participação e outros) }\end{array}$ & 2 & 9 & 23 & 60 & 94 \\
\hline Suspensão e Rescisão Contratuais & & & & \\
\hline $\begin{array}{l}\text { Rol de Procedimentos e Coberturas (geográfica e } \\
\text { assistencial) }\end{array}$ & 2 & 9 & 14 & 50 & 75 \\
\hline Documentos de Entrega Obrigatória ao Consumidor & 1 & 3 & 18 & 19 & 41 \\
\hline Mensalidade ou Contraprestação Pecuniária & 1 & 8 & 7 & 23 & 39 \\
\hline $\begin{array}{l}\text { Contratação/Adesão, Vigência, Manutenção e } \\
\text { Renovação }\end{array}$ & 1 & 3 & 8 & 18 & 30 \\
\hline Migração, Adaptação e Sucessão Contratuais & 0 & 3 & 6 & 11 & 20 \\
\hline Reajuste por Variação de Custos & 0 & 3 & 6 & 15 & 24 \\
\hline Carência & 0 & 3 & 4 & 13 & 20 \\
\hline Portabilidade de Carências & 1 & 2 & 3 & 10 & 16 \\
\hline Reajuste por Mudança de Faixa Etária & 0 & 2 & 5 & 6 & 13 \\
\hline Itens Obrigatórios e Cláusulas Contratuais & 0 & 1 & 4 & 7 & 12 \\
\hline Inclusão de Dependentes do Consumidor & 0 & 3 & 3 & 4 & 10 \\
\hline Demitidos, Exonerados e Aposentados & 0 & 1 & 2 & 7 & 10 \\
\hline $\begin{array}{l}\text { Doença ou Lesão Preexistente, Cobertura Parcial } \\
\text { Temporária e Agravo }\end{array}$ & 0 & 1 & 2 & 4 & 7 \\
\hline Reajuste por Sinistralidade & 0 & 0 & 1 & 1 & 2 \\
\hline Transferência Voluntária & 21 & 104 & 279 & 609 & $\mathbf{1 . 0 1 3}$ \\
\hline Regimes Especiais (Direção Técnica e Direção Fiscal) & 0 & 0 & 0 & 0 & 0 \\
\hline Falência ou Insolvência Civil & & 0 & 0 & 0 & 0 \\
\hline Total Geral & & & 0 & 0 \\
\hline For & & & & \\
\hline
\end{tabular}

Fonte: Elaboração própria. 
É importante destacar que os campos disponíveis no banco dados da ANS, preenchidos pelos próprios beneficiários no ato de envio dos e-mails, apresentam informações referentes a: 1) data de atendimento; 2) meio de atendimento; 3 ) tipo de atendimento; 4) número da demanda; 5) sexo do beneficiário; 6) idade do beneficiário; 7) município do beneficiário; 8) UF do beneficiário; 9) descrição (texto do e-mail); e 10) tema (categorias propostas pela Central de Atendimento da ANS). Após a definição da amostra, iniciamos a fase de categorização e análise dos dados. A categorização se deu em duas etapas. Na primeira, foi realizada leitura flutuante de parte da amostra com intuito de proporcionar uma familiarização com o material e iniciar o processo de sistematização dos dados. $\mathrm{Na}$ segunda, foi realizada a leitura integral dos 1.013 e-mails, que resultou na classificação destes em cinco grandes categorias: acesso aos serviços; continuidade do cuidado; relaçôes contratuais; informação; e outros. Posteriormente, os e-mails categorizados como "Acesso aos Serviços" e "Continuidade do Cuidado" foram classificados, com o objetivo de qualificar a análise, a partir das subcategorias: negaç̧ão; dificuldade elou imposição de condicionantes; e rede de prestadores restrita.

Para construção dessas categorias de análise, foi desconsiderada a categorização prévia proposta pela ANS, uma vez que a intenção era contribuir com uma perspectiva que tenha como foco o debate acerca da qualidade e da integralidade. Desse modo, é importante também ressaltar que, ao considerar a complexidade da discussão e as questões acerca da temática da satisfação do beneficiário sob a perspectiva da qualidade e da integralidade, o modo como se efetivam as práticas de cuidado e seus efeitos, como a resolutividade das demandas, está diretamente relacionado à possibilidade de acessar serviços e procedimentos contratados e à possibilidade de o beneficiário continuar o cuidado sem que precise passar por constrangimento ou sofrer algum agravo à sua saúde.

\section{Resultados}

A limitação dos campos restringe a possibilidade de uma caracterização mais detalhada da população, uma vez que não temos acesso a dados socioeconômicos e de escolaridade. Entretanto, ela nos permite afirmar que a amostra é formada majoritariamente por mulheres (60\% das demandantes) e que a distribuição entre os habitantes das regiōes metropolitanas e dos municípios do interior é equilibrada ( $47,8 \%$ e $52,2 \%$, respectivamente). 
Em relação à distribuição por faixa etária, tendo como parâmetro as faixas definidas a partir de $1^{\circ}$ de janeiro de 2004 , destaca-se a concentração entre os sujeitos de 29 a 43 anos (44,8\%). Há que se ressaltar que a faixa etária com o maior número de solicitações/reclamações é dos beneficiários com mais de 59 anos (18,9\%), seguida pelas faixas de 34 a 38 anos e 29 a 33 (16,5\% e 15,3\% respectivamente), como demonstra o gráfico a seguir.

Gráfico 1. Distribuição da porcentagem (\%) total dos beneficiários dos e-mails selecionados de acordo com as faixas etárias previamente definidas que participaram da amostra dos e-mails enviados para a Central de Relacionamentos da ANS, Região Sudeste, 2014-2015

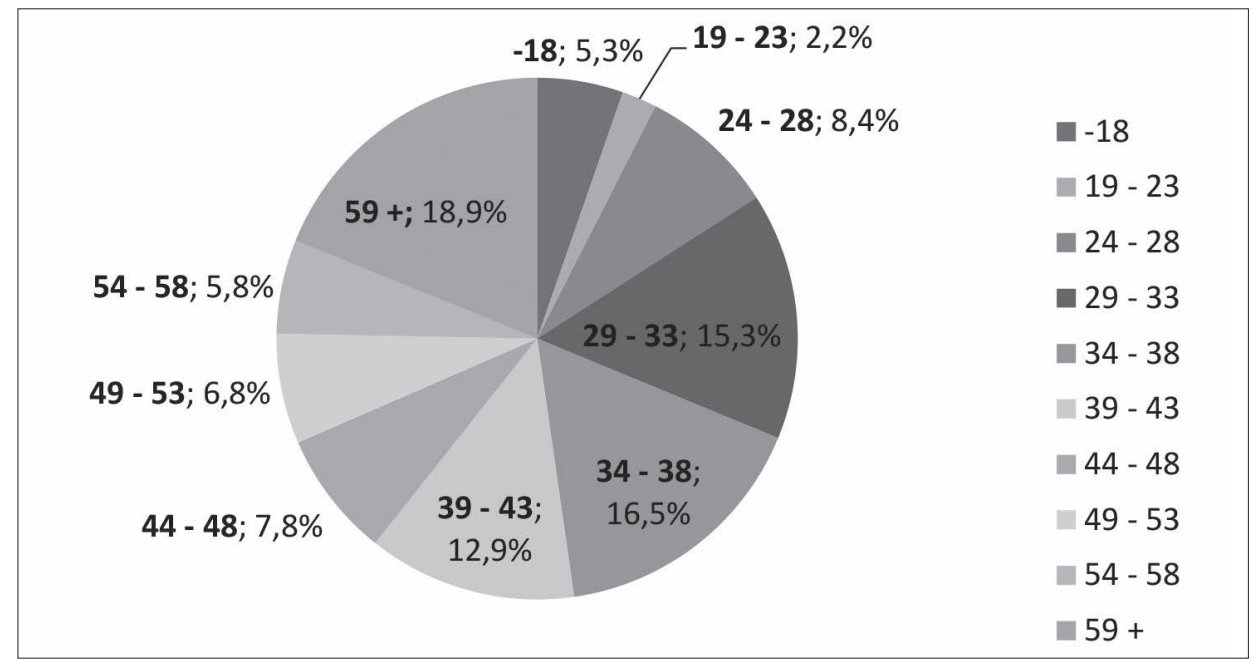

Fonte: Elaboração própria.

Em relação ao conteúdo, 341 e-mails (34\%) referem-se à categoria "Relações Contratuais", que contempla questôes como: reajuste, cobrança indevida, reembolso, portabilidade, cancelamento de contrato, documentos necessários, etc. Em 274 e-mails (27\%), os beneficiários relatam dificuldade e/ou impossibilidade de acesso a um serviço, profissional, procedimento ou tratamento, referente a um primeiro contato. Esses e-mails, que, em geral, se referem a uma demanda para início de um tratamento ou realização de procedimento(s) específico(s), foram categorizados como "Acesso aos Serviços".

Considerando ainda a satisfação do beneficiário da perspectiva da qualidade e da integralidade, 178 mensagens (18\%) relatam problemas em relação à "Continuidade do Cuidado". Trata-se da dificuldade ou impossibilidade de dar prosseguimento ao 
acesso a serviços, profissionais e procedimentos; em geral, referem-se a serviços prescritos por profissionais que já acompanhavam o beneficiário.

A categoria "Informação" agrega 143 e-mails (14\%) que solicitavam informação, sem nenhuma queixa específica. Finalmente, na categoria "Outros", foram alocados os 77 e-mails (8\%) que não continham nem pedido de informação, nem queixa específica, nem referência a relaçôes contratuais, nem problemas relacionados ao acesso ou à continuidade do cuidado.

Gráfico 2. Distribuição da porcentagem (\%) total dos beneficiários dos e-mails selecionados segundo as categorias gerais de análise que participaram da amostra dos e-mails enviados para a Central de Relacionamentos da ANS, Região Sudeste, 2014-2015

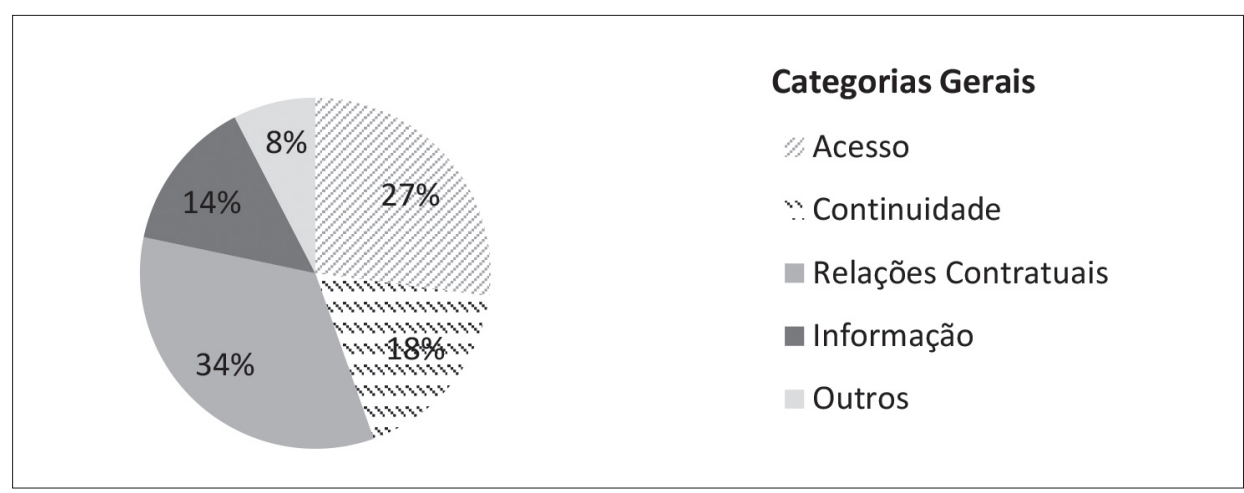

Fonte: Elaboração própria.

Quando nos aproximamos dos conteúdos das mensagens relativas ao acesso aos serviços, percebemos questões específicas que não se referiam apenas à negação direta do acesso por parte das operadoras, que se limitava a 30\% dos casos (81 e-mails). Destacamos que 43\% (118 e-mails) relatavam a dificuldade/ impossibilidade de acessar os serviços devido à imposição de condicionantes, como solicitação repetida para entrega de laudos, relatórios, documentos, avaliação por perícia, etc.; e por problemas de comunicação entre operadoras e beneficiários, como disponibilização de informaçôes contraditórias, dificuldade de estabelecer contato ou obter retorno sobre solicitações realizadas. Os $27 \%$ restantes (75 e-mails) vinculavam o não acesso aos serviços à restrição da rede de prestadores. 

de acordo com a subcategorização da amostra dos e-mails enviados para a Central de Relacionamentos da ANS, Regiāo Sudeste, 2014-2015

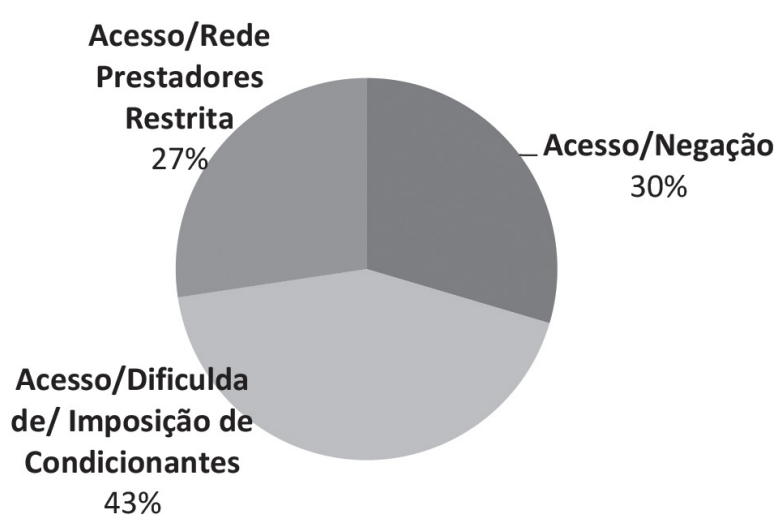

Fonte: Elaboração própria.

Em relação à continuidade do cuidado, é importante destacar que a maioria das mensagens, 56\% (99 e-mails) relatava que a descontinuidade do cuidado era referente a dificuldades ou à imposição de condicionantes para sua manutenção. Para 34\% dos beneficiários (61 e-mails), a continuidade foi negada formalmente pela operadora, e em apenas $10 \%$ dos casos (17 e-mails) a descontinuidade foi decorrente da restrição da rede de prestadores.

Gráfico 4. Distribuição da porcentagem (\%) total na categoria "Continuidade do Cuidado", de acordo com a subcategorização da amostra dos e-mails enviados para a Central de Relacionamentos da ANS, Região Sudeste, 2014-2015

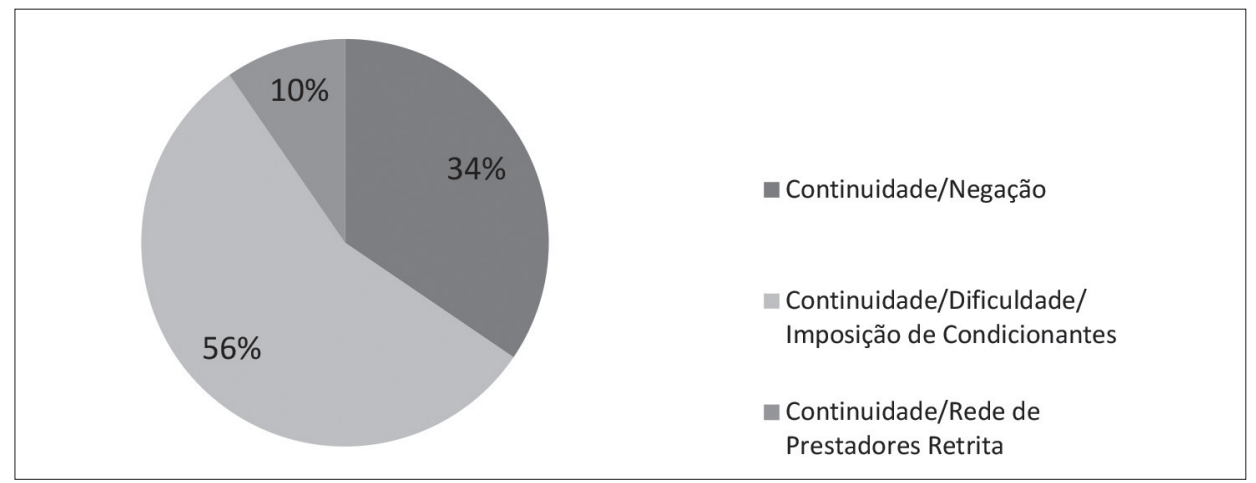

Fonte: Elaboração própria. 


\section{Análise e discussão dos resultados}

A predominância das questôes relacionadas às relações contratuais e à informação (gráfico 2) apontadas nos e-mails dos beneficiários apresenta-se congruente tanto com a produção acadêmica acessada mediante a revisão integrativa realizada na primeira etapa deste estudo, como pelo discurso de alguns servidores, que, durante os grupos focais realizados na terceira etapa, nos confirmam o modo como historicamente vem sendo construída a missão da ANS. Essas informações, em conjunto, são potentes no esclarecimento de que a atuação da agência reguladora, de maneira geral, se baseia tradicionalmente na regulação das relações comerciais entre consumidores e prestadores de serviço de saúde, sendo propiciada pelo esforço inicial direcionado para o cumprimento das cláusulas contratuais e consequente garantia do acesso aos serviços. Posicionamento que ganha visibilidade crescente junto ao público beneficiário e termina por se configurar como função de excelência da agência reguladora (ALVES; BAHIA; BARROS, 2009; GARBIN et al., 2013).

O contato com os servidores que participaram do estudo, reforçado por alguns estudos realizados na revisão bibliográfica, nos faz crer que essa imagem calcada na defesa dos direitos dos consumidores, por sua vez, é reforçada pelo crescente investimento da instituição no combate ao que se convencionou nomear de "assimetria da informação", cujo principal instrumento tem sido a divulgação de informações geralmente direcionadas para a qualificação de um consumo que se quer "consciente". Esforço institucional que se direciona tanto no sentido de auxiliar os beneficiários na escolha das operadoras e sua rede de prestadores, amparados então pela divulgação de indicadores econômico-financeiros que apontam o índice de sustentabilidade e estabilidade de cada empresa, como pela tentativa de esclarecimento dos beneficiários quanto aos limites e possibilidades de acesso aos serviços de acordo com as características específicas dos planos contratados, evitando assim uma suposta demanda infinita (SATO, 2007; VERAS, 2011).

A questão da informação, vista sob essa perspectiva, tende a priorizar os esclarecimentos a respeito da legislação vigente, das cláusulas contratuais e da questão tecnológica, com o intuito de conscientizar os beneficiários para a utilização dos recursos de modo equilibrado perante uma necessidade supostamente objetiva. Nesse aspecto, a temática parece balizar-se por uma via unidirecional, com destaque para a lógica "especialistas-beneficiários", em que 
parece ser pouco valorizado o saber do usuário acerca do próprio processo de

adoecimento e, portanto, da singularidade de suas demandas para a qualificação e resolutividade das práticas de cuidado.

Diante disso, neste trabalho, optamos por destacar a análise das questôes referentes ao "acesso aos serviços" e à "continuidade do cuidado", aspectos que acreditamos ser fundamentais para pensarmos a satisfação do beneficiário na perspectiva da qualidade e integralidade.

No que se refere à imposição de condicionantes para o acesso aos serviços, o discurso dos beneficiários aponta para uma crítica à própria forma de organização do sistema. A rigidez burocrática parece impedir o uso dos serviços contratados no tempo necessário para a resolução das demandas por cuidado, ao mesmo tempo em que a centralidade das especialidades e procedimentos não permite a integralidade do cuidado. Além disso, os beneficiários se queixam de que, apesar da exigência de muitos documentos e perícias, geralmente não há um olhar cuidadoso e diferenciado para as situações que eles entendem como específicas e singulares. Nesse sentido, a imposição de condicionantes parece produzir um sentimento de negligência com a singularidade de cada demanda e suas urgências.

Percebemos assim que a demanda por um olhar diferenciado, de acordo com a singularidade de cada caso clínico, toca ao mesmo tempo na questão dos conflitos entre operadoras e prestadores. Em termos gerais, tais conflitos são ocasionados pela tensão entre a autonomia técnica requerida pelo profissional, que conta, na maioria das vezes, com a credibilidade do beneficiário, e a relação contratual estabelecida entre as partes. Esta, inclusive, em grande parte das vezes, é utilizada pelas operadoras na tentativa de reduzir os custos, o que muitas vezes acaba por inviabilizar ou dificultar tanto o acesso aos serviços como a continuidade do cuidado.

A estratégia de redução de custos, por sua vez, inclui também o próprio regime de remuneração dos prestadores de serviço credenciados. Diante dos preços relativamente baixos referentes ao pagamento de consultas, eles acabam não só por sobrecarregar suas agendas, mas também por aumentar o número de solicitações de exames e procedimentos que nem sempre parecem indispensáveis, mas que acabam funcionando como uma possibilidade complementar de aumentar as receitas. Essas ações dificultam a produção de um olhar mais singular e humanizado e reafirmam a lógica procedimento-centrada, atingindo 
diretamente o beneficiário, que tem seu acesso dificultado e seu tempo de consulta clínica reduzido, enquanto seu itinerário terapêutico se alonga devido à solicitação dos mais variados exames e procedimentos.

Além disso, muitos foram os e-mails que citavam os problemas de comunicação com a operadora e alguns prestadores como fator de dificuldade ou mesmo impedimento do acesso aos serviços, geralmente ocasionando prejuízos significativos, como a perda de prazos para cirurgias e outros procedimentos previamente agendados que dependem de autorização. Nesse contexto, o mau funcionamento dos canais de comunicação com os beneficiários parece naturalizado ou não problematizado, fato que parece servir como justificativa para o prolongamento dos prazos dos procedimentos que se fazem necessários ou que são solicitados no processo de cuidado.

Percebemos que, apesar do acesso às especialidades e procedimentos ganhar maior visibilidade, devido à importância da dimensão da garantia do direito do consumidor, a garantia do direito à saúde, a partir da perspectiva da qualidade e da integralidade, se apresenta de modo mais complexo. Dessa perspectiva, observamos que a demanda dos beneficiários geralmente vai além das questôes contratuais, e também aborda o vínculo estabelecido com os profissionais, tocando em questōes que vão desde a reivindicação do acesso a uma rede credenciada próxima e resolutiva até a reafirmação da relação de confiança e credibilidade construída com os profissionais que constituem essa rede. Nesse contexto, o gerenciamento do setor, levado a cabo pelas operadoras, geralmente desconsidera o entendimento das pessoas sobre a qualidade da atenção, que, em termos gerais, envolve critérios baseados no atendimento de necessidades diversas e singulares, incluindo o acesso e manutenção de uma rede conveniada local mais ampliada.

De certa forma, entendemos que a reclamação acerca do acesso também fala da impossibilidade da manutenção do vínculo. No sistema de saúde suplementar, ao contrário do sistema público, não há um arranjo que favoreça a constituição de linhas de cuidado focadas em estratégias de promoção, como acontece na Atenção Básica, por exemplo, o que termina por determinar que o atendimento seja focado nos especialistas e nos procedimentos. Somados a isso, a restrição/ redução e o descredenciamento recorrente da rede de prestadores, muitas vezes sem o devido aviso prévio, colabora para que o beneficiário perca recorrentemente o vínculo, mesmo que mínimo e precário, obtido pelo acompanhamento de 
alguns especialistas, como os ginecologistas no caso das mulheres e os pediatras no caso das crianças, para citar um exemplo comum.

Temos então que algumas das principais questôes que se colocam para a categoria "Acesso" e suas respectivas subcategorias (gráfico 3), também se colocam para a categoria "Continuidade do cuidado" (gráfico 4). Nesta, aparecem questôes como: novas solicitações de documentos, perícias e autorizações para tratamentos e processos já iniciados e em curso; beneficiários internados para algum tipo de intervenção para os quais a operadora não libera nem nega o procedimento; problemas de comunicação dos beneficiários com as operadoras (operadoras simplesmente não respondem ou protelam-se infinitamente as respostas), situações em que os beneficiários veem os prazos de suas solicitações não cumpridos e estendidos ao absurdo; beneficiários que iniciam o tratamento e, no meio do processo, recebem negativa de cobertura para um procedimento específico ou material; conflitos entre prestadores e operadoras que impedem a continuidade do cuidado em curso.

Precisamos considerar que, como se trata de um cuidado prestado por uma rede de serviços conveniados, é bastante comum que o beneficiário, ao longo de um tratamento, necessite mudar de prestador. Contudo, tal configuração de rede não possibilita o cuidado integral. Nesse aspecto, os relatos dos beneficiários trazem muitos casos nos quais essa necessidade de mudança de especialidadeprestador para continuar seu cuidado implica a interrupção do tratamento por não haver em sua rede conveniada a especialidade demandada. Na maior parte dos casos, a única alternativa que lhes resta é buscar outro especialista, o que geralmente implica um deslocamento inviável. Por vezes também, o prestador com o qual o beneficiário tem vínculo é descredenciado, e por força de contrato, este se vê obrigado a procurar outro profissional em um processo custoso em todos os aspectos, desde a questão do tempo, que muitas vezes é fatal, até a resolutividade de sua demanda e o desgaste físico e emocional, elementos que certamente impactam na sua saúde.

A integralidade fala, portanto, de um tempo que difere, e muito, do tempo da burocracia e da clara imposição de dificuldades para a continuidade do cuidado. Essa temporalidade convocada pela integralidade implica uma necessidade de cuidado que ultrapassa as cláusulas de um contrato. Aqui, como no caso do acesso, o que está em jogo são histórias e demandas singulares. Na continuidade 
542 do cuidado, ainda há alguns agravantes, como as interrupções de tratamentos, por vezes extremamente complexos, como os casos de tratamento oncológico, para citar um exemplo bastante comum. Além disso, é importante ressaltar que, embora a garantia ao acesso seja fundamental, os beneficiários apontam para a necessidade de lidar com um serviço ou profissional no qual tenham confiança e que expressem garantias de continuidade do cuidado.

A satisfação do beneficiário, quando observada pela perspectiva da qualidade e da integralidade, impõe, portanto, a necessidade de construção de indicadores que ultrapassem tanto a concepção de que falta informação ao beneficiário, quanto a noção de rede, geralmente restrita a pontos de atenção dos serviços conveniados. Esses indicadores precisariam, assim, considerar o que faz sentido para o beneficiário, como os vínculos estabelecidos com os profissionais do cuidado, contratos mais explícitos, garantia do acesso e, principalmente, garantia de continuidade do cuidado.

\section{Considerações finais}

Ao analisar especificamente a demanda dos beneficiários da Saúde Suplementar, sob a perspectiva da qualidade e da integralidade, colocando em questão os requisitos que compõem sua satisfação, temos que a noção do direito à saúde como bem público emerge em meio a um paradoxo e aponta para questóes que, à primeira vista, parecem ser irreconciliáveis, uma vez que a relação entre beneficiários, operadoras e prestadores é condicionada especialmente pelo mercado e pelos interesses econômicos dos últimos. Desse modo, a partir da lógica de funcionamento segundo a qual o setor de saúde suplementar vem sendo estruturado, a garantia da integralidade parece impossível de ser alcançada, haja vista a habitual prática de segmentação da clientela com base na capacidade de pagamento, e não por suas necessidades (SESTELO; SOUZA; BAHIA, 2014), emergindo, portanto, como um desafio para a regulação do setor.

Ainda que os planos de saúde sejam vendidos com a promessa de acesso a especialistas/procedimentos/serviços sempre que necessário e/ou demandado, configurando-se como uma alternativa à precariedade do Sistema Único de Saúde (RUYZ; MAXTA, 2012; DILÉLIO et al., 2014), percebemos, a partir da leitura dos e-mails encaminhados para o canal de relacionamento da ANS, 
que essa não é uma realidade do setor. Ao contrário disto, o setor de saúde

suplementar, ao reafirmar a lógica biomédica e da fragmentação do cuidado, acaba por produzir uma demanda crescente por procedimentos e serviços cada vez mais especializados, de alta densidade tecnológica e alto custo. Custo que, diante da lógica de ampliação dos lucros, deve ser sempre reduzido.

Neste contexto, a análise dos e-mails dos beneficiários aponta que algumas das estratégias de redução de custos têm afetado a qualidade e afrontado a integralidade do cuidado. Os relatos apontam que, para além da negação do acesso aos serviços e procedimentos, os beneficiários também se veem diante da restriçãao da continuidade do cuidado. A negação do acesso e restrição da continuidade do cuidado ocorrem por meio de diferentes situações, que vão desde a negação/não aprovação de um serviço/procedimento até a ausência, restrição ou insuficiência da rede de prestadores, passando por diversas situações em que o acesso e a continuidade são impedidos pela imposição de condicionantes (como exigências de laudos, documentos, avaliação por peritos) e/ou dificuldades (como informações parciais, contraditórias e/ou equivocadas; canais de comunicação ineficientes; restrição do acesso a informações, etc.). Tal quadro aponta a necessidade de se fiscalizar se tais dificuldades não são estratégias deliberadas para redução de custos.

Desse modo, por um lado, a análise da satisfação do beneficiário da saúde suplementar sob a perspectiva da qualidade e integralidade nos coloca o desafio de questionar a própria estruturação do setor de saúde suplementar, cujos contratos se baseiam na definição de um rol de procedimentos com diferentes níveis de abrangência, mas ainda assim limitados. Por outro, ela nos impõe a necessidade de ressaltar quando as estratégias de redução de custos passam a se configurar como instrumento de restrição ao próprio direito à saúde, para além do respeito necessário ao direito do consumidor. ${ }^{3}$

\section{Referências}

ALVES, D. C.; BAHIA, L.; BARROSO, A. F. O papel da Justiça nos planos e seguros de saúde no Brasil. Cad. Saúde Pública. Rio de Janeiro, v. 25, n. 2, p. 279-290, fev. 2009.

ANDRADE, M. V.; MAIA, A. C.; RODRIGUES, C. G. Indicadores de gastos com serviços médicos no setor de saúde suplementar no Brasil. Rev. bras. estud. popul., São Paulo, v. 30, supl., p. S103-S117, 2013. 
BRASIL. Constituição da República Federativa do Brasil. Brasília, DF: Senado Federal: Centro Gráfico, 1988.

CARVALHO, R. R. P.; FORTES, P. A. de C.; GARRAFA, V. A saúde suplementar em perspectiva bioética. Rev. Assoc. Med. Bras., São Paulo, v. 59, n. 6, Dec. 2013.

DILÉLIO, A. S. et al. Padrões de utilização de atendimento médico-ambulatorial no Brasil entre usuários do Sistema Único de Saúde, da saúde suplementar e de serviços privados. Cad. Saúde Pública, Rio de Janeiro, v. 30, n. 12, p. 2594-2606, dez. 2014.

ESCRIVÃO JÚNIOR, A.; KOYAMA, M. F. O relacionamento entre hospitais e operadoras de planos de saúde no âmbito do Programa de Qualificação da Saúde Suplementar da ANS. Ciênc. Saúde Coletiva. Rio de Janeiro, v. 12, n. 4, p. 903-914, ago. 2007.

FONTANELLA, B. J. B.; RICAS, J.; TURATO, E. R.. Amostragem por saturação em pesquisas qualitativas em saúde: contribuiçôes teóricas. Cad. Saúde Pública, Rio de Janeiro, v. 24, n. 1, p. 17-27, jan. 2008.

FREITAS, P. de S. S. et al. A percepção dos usuários sobre a oferta de programas de promoção da saúde e prevenção de doenças: o caso de uma operadora de autogestão. Physis, Rio de Janeiro, v. 21, n. 2, p. 449-459, 2011.

FREITAS, R. M. de et al. Estudo dos modelos assistenciais praticados por operadoras de planos privados de saúde. Physis, Rio de Janeiro, v. 21, n. 4, p. 1561-1577, dez. 2011.

GARBIN, D. et al. Odontologia e Saúde Suplementar: marco regulatório, políticas de promoção da saúde e qualidade da atenção. Ciênc. Saúde Coletiva. Rio de Janeiro, v. 18, n. 2, p. 441-452, fev. 2013.

GERSCHMAN, S. Políticas comparadas de saúde suplementar no contexto de sistemas públicos de saúde: União Européia e Brasil. Ciênc. Saúde Coletiva. Rio de Janeiro, v. 13, n. 5, p.1441-1451, out. 2008.

MALTA, D. C. et al. Perspectivas da regulação na saúde suplementar diante dos modelos assistenciais. Ciênc. Saúde Coletiva, Rio de Janeiro, v. 9, n. 2, p. 433-444, jun. 2004.

MARTINS, A. A. et al. A produção do cuidado no Programa de Atenção Domiciliar de uma Cooperativa Médica. Physis, Rio de Janeiro, v. 19, n. 2, p. 457-474, 2009.

MENESES, C. S. et al. Os usuários e a transição tecnológica no setor de saúde suplementar: estudo de caso de uma operadora de plano de saúde. Ciênc. Saúde Coletiva, Rio de Janeiro, v. 18, n. 1, p. 57-66, jan. 2013.

PIETROBON, L.; PRADO, M. L. do; CAETANO, J. C. Saúde suplementar no Brasil: o papel da Agência Nacional de Saúde Suplementar na regulação do setor. Physis, Rio de Janeiro, v. 18, n. 4, p. 767-783, 2008. 
PINHEIRO, R.; SILVA JUNIOR, A. G. da. Marco teórico-conceitual. In: PINHEIRO,

R. et al. (Orgs.). Integralidade e saúde suplementar: formação e práticas avaliativas Rio de Janeiro: IMS/UERJ: CEPESC: ABRASCO, 2007. p. 17-46.

. Integralidade e Saúde Suplementar: uma experiência de pesquisa interdisciplinar e colaborativa. In: PEREIRA, R. C. SILVESTRE, R. M. (Org.). Regulação e modelos assistenciais em saúde suplementar: produção científica de Centros Colaboradores da ANS2006/2008. Brasília. Organização Pan Americana de Saúde. 2009. p. 277-338.

PORTELA, M. C. et al. Estrutura e qualidade assistencial dos prestadores de serviços hospitalares à saúde suplementar no Brasil. Cad. Saúde Pública, Rio de Janeiro, v. 26, n. 2, p. 399-408, fev. 2010.

RUYZ, M. de S.; MAXTA, B. S. B. Terapeutas Ocupacionais na Saúde suplementar no município de Jundiaí-SP. Cad. Ter. Ocup. UFSCar, São Carlos, v. 20, n 3, p 435-441, 2012.

SANTOS, F. P. dos; MALTA, D. C.; MERHY, E. E. A regulação na saúde suplementar: uma análise dos principais resultados alcançados. Ciência \& Saúde Coletiva, Rio de Janeiro, v. 13 , n. 5, p. $1463-1475,2008$.

SATO, F. R. L. A teoria da agência no setor da saúde: o caso do relacionamento da Agência Nacional de Saúde Suplementar com as operadoras de planos de assistência supletiva no Brasil. RAP, Rio de Janeiro, v. 41, n. 1, p. 49-62, jan/fev. 2007.

SILVA, J. P. V. da; BATISTELLA, C.; GOMES, M. de L. Problemas, Necessidades e Situação de Saúde: uma revisão de abordagens para a reflexão e ação da equipe de saúde da família. In: FONSECA, A. F. (Org.). O território e o processo saúde-doença. Rio de Janeiro: EPSJV/Fiocruz, 2007.

SILVA JUNIOR, A. G. da et al. Experiências de avaliação do setor suplementar de saúde: contribuições da integralidade. Ciênc. Saúde Coletiva, Rio de Janeiro, v. 13, n. 5, p. 14891500, out. 2008 .

SISSON, M. C. et al. Satisfação dos usuários na utilização de serviços públicos e privados de saúde em itinerários terapêuticos no sul do Brasil. Interface, Botucatu, v. 15, n. 36, p. 123-136, mar. 2011.

UGÁ, M. A. D. et al. Mecanismos de microrregulação aplicados por operadoras de planos de saúde sobre hospitais privados. Rev. Saúde Pública, São Paulo, v. 43, n. 5, p. 832-838, out. 2009. VERAS, R. P. Experiências e tendências internacionais de modelos de cuidado para com o idoso. Ciênc. Saúde Coletiva, Rio de Janeiro, v. 17, n. 1, p. 231-238, jan. 2012.

. Estratégias para o enfrentamento das doenças crônicas: um modelo em que todos ganham. Rev. Bras. Geriatr. Gerontol., Rio de Janeiro, v. 14, n. 4, p. 779-786, 2011.

VERAS, R. P. et al. A assistência suplementar de saúde e seus projetos de cuidado para com o idoso. Ciênc. Saúde Coletiva, Rio de Janeiro, v. 13, n. 4, p. 1119-1126, ago. 2008. 


\section{Notas}

${ }^{1}$ Pesquisa financiada com recursos provenientes do Edital 005/2014 (Cooperação entre a Agência Nacional de Saúde Suplementar e a Organização Pan-Americana de Saúde/Organização Mundial de Saúde). Não há conflito de interesses.

${ }^{2}$ A implantação da Notificação de Intermediação Preliminar (NIP) foi uma medida de resolução extrajudicial de conflitos proposta pela ANS, que objetiva a solução consensual entre consumidores e operadoras de planos privados de assistência à saúde, e corresponde ao esforço metodológico direcionado para a análise de demandas dos consumidores. Segundo os técnicos da ANS que acompanharam a realização desta pesquisa, a implementação dessa resolução (Resolução Normativa no 226) aumentou a resolutividade dos conflitos entre beneficiários e operadoras em $80 \%$, contribuindo significativamente para a mudança da percepção dos beneficiários sobre a ANS.

${ }^{3}$ R. F. Daros participou da concepção do artigo, redação análise interpretação dos dados e aprovou a versão final a ser publicada. R. da S. Gomes participou da concepção do artigo, redação análise interpretação dos dados e aprovou a versão final a ser publicada. F. H. da Silva participou da concepção do artigo, redação análise interpretação dos dados e aprovou a versão final a ser publicada. Tatiana Coelho Lopes participou da concepção do artigo, redação análise interpretação dos dados e aprovou a versão final a ser publicada. 
Satisfaction of the beneficiary of supplemental health in the perspective of quality and integral care

This study aimed to analyze the concept of quality from the beneficiaries demands of the Supplementary Health, whose main bias the issue of integral care, considering the relationship between satisfaction, information asymmetry and health care. We analyzed a sample of 1,013 emails of 19,969 that were sent to the Supplemental Health National Agency Relationship Center, between March 18, 2014 and March 19, 2015, relating to complaints of beneficiaries who reside in Southeastern Brazil, resulting in the following categorization: Access to Health Services and Continuity of Care, with the following subcategories: Denial; Difficulty and / or Conditioning Constraints; and Restricted Providers Network. Beneficiaries emphasized aspects related to access to services and continuity of care, noting that in addition to the denial of access to services and procedures, they are faced with the restriction of continuity of care. The results place us the challenge to question the structure of the supplemental health sector, whose contracts are based on the definition of a list of procedures and cost reduction strategies are configured as a restraint instrument to the right to health itself, in addition to the necessary respect to consumer's right.

> Key words: supplemental health; beneficiaries' satisfaction; quality; integral care. 